\title{
Evidence for early impairment of verbal intelligence in Duchenne muscular dystrophy
}

\author{
GAYLE G. MARSH and THEODORE L. MUNSAT
}

From the Departments of Psychiatry and Neurology, Reed Neurological Research Center, University of California at Los Angeles; and the Department of Neurology, University of Southern California, Los Angeles

\begin{abstract}
Marsh, G. G., and Munsat, T. L. (1974). Archives of Disease in Childhood, 49, 118. Evidence for early impairment of verbal intelligence in Duchenne muscular dystrophy. Intelligence tests were carried out on 34 boys with muscular dystrophy. The 16 who were mildly physically disabled scored significantly lower on the verbal scale (mean $85 \cdot 3$ ) of the Wechsler Intelligence Scale for Children (WISC) than on the performance scale (mean $97 \cdot 6$ ). The 18 who were moderately or markedly physically disabled showed no significant difference between their mean verbal $(87 \cdot 6)$ and performance $(89 \cdot 7)$ scores. The results are interpreted as suggesting an early and nonprogressive impairment of verbal intelligence in Duchenne muscular dystrophy.
\end{abstract}

The occurrence of intellectual impairment above the expected frequency in children with Duchenne muscular dystrophy (DMD) has been amply documented in published reports (Dubowitz and Crome, 1969; Prosser, Murphy, and Thompson, 1969; Zellweger and Niedermeyer, 1965). There has been less agreement about the nature of this intellectual impairment, however. Though DMD, a progressive neuromuscular disease, would be expected to impair scores on tests requiring use of hands, Zellweger and Niedermeyer (1965) and Zellweger and Hanson (1967) have observed that dystrophic children often obtain performance IQ scores that are higher than their verbal IQ scores. The majority of boys in these two studies were relatively unimpaired in their motor functioning, with only a small number of them in wheelchairs. In studying dystrophic children confined to wheelchairs, Sherwin and McCully (1961) anticipated greatly lowered performance IQ scores but found very little discrepancy between the verbal and performance IQ scores. 4 of the boys, despite considerable motor impairment, obtained higher performance IQs than verbal IQs.

Prosser et al. (1969) analysed verbal and performance IQ scores for a group of 39 dystrophics, ranging in age from 5 to 18 . No significant

Received 13 August 1973. difference was found between the verbal and performance IQ scores. The apparent contradiction between Prosser et al.'s findings and the observations mentioned above may be related to differences in the severity of motor disability in their respective samples. Severe motor disability would be expected to lower scores on performance subtests and, in the case of DMD, should be more noticeable in the older age range as the disease progresses and the child becomes less agile in using his hands. Some support for this appears in Zellweger and Niedermeyer's (1965) study of DMD children, aged 3 to 16 , who were relatively free from motor impairments; 16 of their 23 patients scored higher on the performance subtests. In the Sherwin and McCully study (1961) in which all children, aged 10 to 15 years, were wheelchair dependent but able to attend regular public schools, the motor disability was greater and only 4 of the 15 dystrophic boys obtained performance IQ scores higher than verbal scores. Prosser et al. do not report the effect of disease severity on the verbal and performance IQ scores separately. However, because their patients ranged in age up to 18 years, there is a strong possibility that many of the older dystrophics were more severely impaired in the use of their hands, which may have suppressed scores on the performance subtests more than in the other studies.

In no published study have the dystrophic 


\section{Evidence for early impairment of verbal intelligence in Duchenne muscular dystrophy}

children's verbal and performance intelligence test results been based exclusively on the complete Wechsler Intelligence Scale for Children (WISC) (Wechsler, 1949) and examined in light of their disability ratings. In most studies two and even three different intelligence tests have been administered in order to cover the range of ages in the samples (Allen and Rodgin, 1960; Kozicka, Prot, and Wasilewski, 1971; Prosser et al., 1969; Sherwin and McCully, 1961; Zellweger and Hanson, 1967; and Zellweger and Niedermeyer, 1965). Contrary to the assumption followed by those researchers that intelligence tests such as the WISC, the Wechsler Adult Intelligence Scale (WAIS, Wechsler, 1955), and the Stanford-Binet Intelligence Scale (S-B, Terman and Merrill, 1937) are comparable in estimating IQ means and can be used interchangeably, Hannon and Kicklighter (1970) reported that the WAIS produces a significantly higher IQ score of approximately 7 IQ points over the WISC for 15- to 16-year-olds in the less-thanaverage intelligence range. The WISC was noted to obtain higher scores for the average and aboveaverage adolescents than the WAIS. The S-B has been noted to give higher IQ scores to children of normal mental abilities at the younger age levels (Barclay and Carolan, 1966) than the WISC. Thus, by treating the scores from these tests as equivalent, real differences may have been obscured. For example, because the WISC age range is from 5 years to 15 years 11 months, in order to obtain IQ scores for boys older than 15 years 11 months, the WAIS has to be administered. In Prosser et al.'s study the age range extended to 18 years. The IQ results on their older dystrophic boys which were based on the WAIS possibly contain test-related inflated IQ values which could obscure actual lowering of IQ scores.

The present study was undertaken to investigate further the effect of severity of Duchenne muscular dystrophy on verbal and performance IQ, and to define in more detail the nature of the intellectual deficit in DMD.

\section{Methods and materials}

Subjects. 40 dystrophic boys with a firm diagnosis of DMD established by experienced clinicians were selected for the study. The diagnosis of DMD was established on each child on the basis of at least four of the following criteria: (1) typical clinical signs of Duchenne muscular dystrophy; (2) muscle biopsy consistent with DMD; (3) myopathic electromyogram; (4) raised serum enzymes, especially creatine phosphokinase; (5) consistent pedigree.

The first $\mathbf{4 0}$ available dystrophic boys who met the diagnostic, age, and commuting requirements were asked to participate. Thus, the sample was not strictly random. 6 boys could not be included in the results; 4 were hyperactive and unmanageable in the testing situation; 1 child refused the tests; and one mother reported her child untestable because of mental retardation.

The 34 boys who completed the tests were categorized into two groups based on their physical independence ratings. These ratings were based on 15 daily activities, many of which describe personal grooming, feeding, dressing, writing, speaking, and ambulation. The 5 categories were (1) bedridden, (2) wheelchair with assistance, (3) wheelchair independent, (4) ambulatory limited, and (5) ambulatory unlimited. Categories 4 and 5 were combined to represent the mildly impaired group (group I). Categories 2 and 3 were combined to designate the moderately to markedly impaired group (group II). No patient was in category 1 .

Test. The WISC (Wechsler, 1949) was selected as the test instrument because it offers a verbal IQ based on verbal answers and a performance IQ score based on subtests requiring use of the hands. Another advantage of the WISC is that it converts raw subtest data into mean scaled scores so that performance on the subtests can be compared. The scaled scores have been computed to provide for each subtest a mean scaled score of 10 and SD of 3.

\section{Results}

Descriptive data. Table I gives the characteristics of the 34 dystrophic boys. 26 of the 34 boys attended special schools for handicapped children; the remaining 8 were attending regular schools. The descriptive data in Table I show that the younger the child the less the physcial disability; the older the child the greater the chance he will be wheelchair dependent. This is consistent with the uniform progress of the disease. In the sample of 34 boys, the crucial age appears to be age 9 when the children move into the more disabled category, group II.

In comparing the IQ test results of groups I and II with those of the WISC normative group of 1100 normal boys between the ages of 5 and 15 (Seashore, Wesman, and Doppelt, 1950), it is evident that the two dystrophic groups are considerably lower in IQ scores (Table II). Another way to look at the obtained IQ scores is to compare them with the WISC normative group by converting the obtained IQ score to the corresponding centile rank of the normative group. Group I's verbal IQ of $85 \cdot 3$ (dull normal range) is between the 10th and 20th centiles of the WISC normative group; their performance IQ of 97.6 (average range) is between the 40th and 50th centiles; and full scale IQ of 90.4 (average range) corresponds to the 25th centile. 
TABLE I

Descriptive characteristics of 34 dystrophic boys

\begin{tabular}{|c|c|c|c|c|c|c|c|c|c|}
\hline \multirow[b]{2}{*}{$\begin{array}{l}\text { Case } \\
\text { no. }\end{array}$} & \multirow{2}{*}{\multicolumn{2}{|c|}{$\underset{(y r)}{\text { Age }}(\mathrm{mth})$}} & \multirow[b]{2}{*}{$\begin{array}{c}\text { Age at } \\
\text { diagnosis }(y r)\end{array}$} & \multirow[b]{2}{*}{$\begin{array}{c}\text { Independence } \\
\text { rating }\end{array}$} & \multirow[b]{2}{*}{ Appliancet } & \multirow[b]{2}{*}{ School/class $\ddagger$} & \multicolumn{3}{|c|}{ WISC } \\
\hline & & & & & & & $\begin{array}{l}\text { Verbal } \\
\text { IQ }\end{array}$ & $\begin{array}{c}\text { Performance } \\
\text { IQ }\end{array}$ & $\begin{array}{c}\text { Full scale } \\
\text { IQ }\end{array}$ \\
\hline $\begin{array}{r}1 \\
2 \\
3 \\
4 \\
5 \\
6 \\
7 \\
8 \\
9 \\
10 \\
11 \\
12 \\
13 \\
14 \\
15 \\
16 \\
17 \\
18 \\
19 \\
20 \\
21 \\
22 \\
23 \\
24 \\
25 \\
26 \\
27 \\
28 \\
29 \\
30 \\
31 \\
32 \\
33 \\
34\end{array}$ & $\begin{array}{r}5 \\
6 \\
6 \\
7 \\
7 \\
7 \\
7 \\
8 \\
8 \\
8 \\
8 \\
8 \\
8 \\
8 \\
8 \\
9 \\
9 \\
9 \\
9 \\
9 \\
9 \\
10 \\
10 \\
10 \\
10 \\
10 \\
11 \\
11 \\
11 \\
11 \\
11 \\
12 \\
13 \\
15\end{array}$ & $\begin{array}{r}8 \\
7 \\
10 \\
1 \\
4 \\
10 \\
11 \\
\\
2 \\
2 \\
3 \\
5 \\
7 \\
9 \\
9 \\
\\
\\
2 \\
5 \\
6 \\
9 \\
\\
1 \\
5 \\
6 \\
11 \\
2 \\
2 \\
3 \\
11 \\
7 \\
2\end{array}$ & 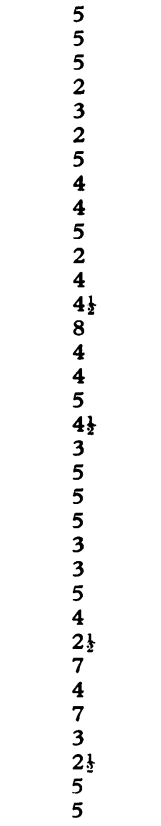 & $\begin{array}{l}5 \\
5 \\
5 \\
4 \\
5 \\
4 \\
4 \\
5 \\
4 \\
4 \\
4 \\
5 \\
4 \\
5 \\
5 \\
2 \\
2 \\
2 \\
3 \\
2 \\
3 \\
3 \\
3 \\
4 \\
2 \\
2 \\
2 \\
3 \\
3 \\
3 \\
2 \\
2 \\
2 \\
2\end{array}$ & $\begin{array}{l}0 \\
0 \\
0 \\
0 \\
0 \\
0 \\
0 \\
0 \\
0 \\
0 \\
0 \\
0 \\
0 \\
0 \\
0 \\
1 \\
1 \\
1 \\
1 \\
18 \\
1 \\
1 \\
1 \\
0 \\
1 \\
1 \\
1 \\
1 \\
1 \\
1 \\
1 \\
1 \\
1 \\
1\end{array}$ & $\begin{array}{l}\mathrm{R} / \mathrm{K} \\
\mathrm{R} / \mathrm{K} \\
\mathrm{R} / \mathrm{K} \\
\mathrm{Sp} / 1 \\
\mathrm{Sp} / 2 \\
\mathrm{Sp} / 2 \\
\mathrm{Sp} / 2 \& 3 \\
\mathrm{R} / 2 \\
\mathrm{Sp} / 2 \\
\mathrm{R} / 2 \\
\mathrm{Sp} / 2 \\
\mathrm{Sp} / 3 \\
\mathrm{Sp} / \mathrm{Ungraded} \\
\mathrm{Sp} / 3 \\
\mathrm{R} / 4 \\
\mathrm{Sp} / 3 \\
\mathrm{Sp} / \mathrm{Ungraded} \\
\mathrm{Sp} / 3 \\
\mathrm{Sp} / 2 \\
\mathrm{Sp} / 4 \\
\mathrm{Sp} / 2 \\
\mathrm{Sp} / 4 \\
\mathrm{Sp} / 4 \\
\mathrm{Sp} / 4 \\
\mathrm{Sp} / 5 \\
\mathrm{Sp} / 5 \\
\mathrm{R} / 5 \\
\mathrm{Sp} / 5 \\
\mathrm{Sp} / 5 \\
\mathrm{Sp} / 6 \\
\mathrm{R} / 7 \\
\mathrm{Sp} / 6 \\
\mathrm{Sp} / \mathrm{Ungraded} \\
\mathrm{Sp} / 9\end{array}$ & $\begin{array}{r}80 \\
65 \\
75 \\
85 \\
92 \\
96 \\
87 \\
104 \\
76 \\
86 \\
67 \\
66 \\
82 \\
87 \\
111 \\
65 \\
79 \\
90 \\
69 \\
80 \\
100 \\
100 \\
109 \\
106 \\
92 \\
91 \\
84 \\
87 \\
99 \\
99 \\
101 \\
85 \\
65 \\
81\end{array}$ & $\begin{array}{r}87 \\
80 \\
79 \\
113 \\
108 \\
110 \\
107 \\
128 \\
83 \\
110 \\
67 \\
80 \\
87 \\
101 \\
93 \\
78 \\
86 \\
100 \\
58 \\
89 \\
100 \\
94 \\
108 \\
128 \\
96 \\
96 \\
89 \\
99 \\
76 \\
104 \\
115 \\
86 \\
65 \\
75\end{array}$ & $\begin{array}{r}82 \\
70 \\
75 \\
98 \\
100 \\
103 \\
96 \\
117 \\
77 \\
97 \\
64 \\
70 \\
83 \\
93 \\
103 \\
68 \\
80 \\
94 \\
60 \\
83 \\
100 \\
97 \\
109 \\
118 \\
93 \\
93 \\
85 \\
92 \\
87 \\
101 \\
109 \\
84 \\
63 \\
76\end{array}$ \\
\hline
\end{tabular}

*See categories 1-5 under Methods and Materials.

$\dagger 0$, none; 1 , wheelchair; 2 , leg braces.

$\ddagger R$, regular school; Sp, special school for the handicapped; K, kindergarten; 1-9, 1st-9th grades.

WISC, Wechsler Intelligence Scale for Children.

TABLE II

Mean age, independence ratings, and mean WISC scores for groups I and II and WISC normative group

\begin{tabular}{|c|c|c|c|c|c|c|c|c|}
\hline & \multicolumn{3}{|c|}{$\begin{array}{c}\text { Group I } \\
\text { (no. }=16 \text { boys) } \\
\text { (mildly impaired) }\end{array}$} & \multicolumn{3}{|c|}{$\begin{array}{c}\text { Group II } \\
\text { (no. }=18 \text { boys) } \\
\text { (moderately to markedly impaired) }\end{array}$} & \multicolumn{2}{|c|}{$\begin{array}{c}\text { WISC normative group } \\
\text { (no. }=1100 \text { boys, } \\
\text { age } 5 \text { to } 15 ; \\
\text { Seashore } \text { et al., 1950) }\end{array}$} \\
\hline & Mean & SD & $t$ & Mean & SD & $\mathbf{t}$ & Mean & SD \\
\hline $\begin{array}{l}\text { Age } \\
\text { Independence rating } \\
\text { Verbal IQ } \\
\text { Performance IQ } \\
\text { Verbal-Performance Score† } \\
\text { Full scale IQ }\end{array}$ & $\begin{array}{r}7 \cdot 92 \\
4 \cdot 50 \\
85 \cdot 31 \\
97 \cdot 56 \\
-12 \cdot 25 \\
90 \cdot 37\end{array}$ & $\begin{array}{r}1 \cdot 08 \\
0 \cdot 51 \\
14 \cdot 03 \\
18 \cdot 18 \\
11 \cdot 40 \\
16 \cdot 51\end{array}$ & $4 \cdot 29 \ddagger$ & $\begin{array}{r}10 \cdot 85 \\
2 \cdot 38 \\
87 \cdot 55 \\
89 \cdot 66 \\
-2 \cdot 11 \\
87 \cdot 44\end{array}$ & $\begin{array}{r}1 \cdot 67 \\
0 \cdot 50 \\
12 \cdot 84 \\
14 \cdot 87 \\
9 \cdot 31 \\
14 \cdot 22\end{array}$ & 0.96 & $\begin{array}{l}101 \cdot 2 \\
100 \cdot 3 \\
100 \cdot 8\end{array}$ & $\begin{array}{l}15 \cdot 3 \\
15 \cdot 6 \\
15 \cdot 6\end{array}$ \\
\hline
\end{tabular}

$\star$ See Methods and Materials.

tRefers to verbal score minus the performance score.

$\ddagger P<0.001$ level. 
Group II's verbal IQ of 87.5 (dull normal range) corresponds to the 20th centile of the WISC normative group; their performance IQ of 89.7 (upper range of dull normal) corresponds to the 25th centile; and their full scale IQ of $87 \cdot 4$ corresponds to the 20th centile.

Evidence for an early and nonprogressive verbal deficit. The dystrophic boys with mild physical disabilities (group I) scored significantly lower on their verbal IQ $(85.3)$ than on their performance IQ $(97 \cdot 6)(t=4 \cdot 29, P<0 \cdot 001)$ (Table II). Since our patients were all males, it is possible that this finding is due to a sex difference based on the assumption that boys generally obtain lower verbal IQs than performance IQs. However, Seashore et al. (1950) have shown that boys in the normative sample obtained comparable means for both verbal and performance IQs $(101 \cdot 2$ for verbal and $100 \cdot 3$ for performance IQs). No significant difference was observed between verbal $(87 \cdot 6)$ and performance $(89 \cdot 7)$ for the group II patients $(P=0.96, P>0.2)$.

Nature of intellectual deficit. Table III presents the mean WISC subtest scores for groups I and II. Though none of the subtest comparisons between the two groups reached statistical significance, the coding task, a performance subtest that requires the patient to write symbols for numbers, came close to being significant $(t=1 \cdot 85$, $0 \cdot 1<\mathrm{P}<0 \cdot 05$.

TABLE III

Mean WISC subtest scores for groups I and II

\begin{tabular}{|c|c|c|c|}
\hline & $\begin{array}{l}\text { Group I } \\
(\text { no. }=16)\end{array}$ & $\begin{array}{c}\text { Group II } \\
(\text { no. }=18)\end{array}$ & $\begin{array}{c}\text { Difference } \\
\text { in } \\
\text { mean scores }\end{array}$ \\
\hline $\begin{array}{l}\text { Verbal subtests } \\
\text { Information } \\
\text { Comprehension } \\
\text { Arithmetic } \\
\text { Similarities } \\
\text { Vocabulary } \\
\text { (Digit span) }\end{array}$ & $\begin{array}{c}7 \cdot 81 \\
7 \cdot 68 \\
7 \cdot 06 \\
7 \cdot 87 \\
7 \cdot 87 \\
(7 \cdot 31)\end{array}$ & $\begin{array}{c}8 \cdot 11 \\
6 \cdot 88 \\
6 \cdot 88 \\
8 \cdot 66 \\
9 \cdot 50 \\
(7 \cdot 05)\end{array}$ & $\begin{array}{l}+0.30 \\
-0.80 \\
-0.18 \\
+0.79 \\
+1.63 \\
-0.26\end{array}$ \\
\hline $\begin{array}{l}\text { Performance subtests } \\
\text { Picture completion } \\
\text { Picture arrangement } \\
\text { Block design } \\
\text { Object assembly } \\
\text { Coding }\end{array}$ & $\begin{array}{r}9 \cdot 37 \\
9 \cdot 06 \\
10 \cdot 87 \\
10 \cdot 31 \\
8 \cdot 80\end{array}$ & $\begin{array}{l}7 \cdot 88 \\
9 \cdot 16 \\
9 \cdot 55 \\
9 \cdot 27 \\
6 \cdot 72\end{array}$ & $\begin{array}{l}-1.49 \\
+0.10 \\
-1.32 \\
-1.04 \\
-2.08\end{array}$ \\
\hline $\begin{array}{l}\text { Verbal IQ } \\
\text { Performance IQ } \\
\text { Full Scale IQ }\end{array}$ & $\begin{array}{l}85 \cdot 31 \\
97 \cdot 56 \\
90 \cdot 37\end{array}$ & $\begin{array}{l}87 \cdot 55 \\
89 \cdot 66 \\
87 \cdot 44\end{array}$ & $\begin{array}{l}+2 \cdot 24 \\
-7 \cdot 90 \\
-2 \cdot 93\end{array}$ \\
\hline
\end{tabular}

Note: Digit span scoreswere no $t$ included in computing individual WISC IQs in the present study.
Group I's lower scores on all the verbal subtests in comparison with their performance subtests appear to be related to a mild impairment in verbally mediated cognitive functioning which is apparent in the early stages of the disease when the patient shows little disability in the use of his hands. A low verbal IQ score with a higher performance IQ score has been associated with reading disability (Clements and Peters, 1962; Ackerman, Peters, and Dykman, 1971) and with impaired reading, spelling, and arithmetic scores (Rourke, Young, and Flewelling, 1971). The verbal deficit in DMD appears to be a relatively generalized one that interferes with verbal subtests measuring fund of general information, practical knowledge and judgement, verbal abstract thinking, expressive vocabulary, mentally calculated arithmetic problems, and rote learning. Partial corroborative evidence of a generalized intellectual deficit may be inferred from the fact that 23 of the 34 dystrophics were placed in school classes below those of their age-related peers (Table I).

Group II, the older and more physically disabled dystrophics, showed a similar but not as clear-cut a pattern, possibly because their physical disability is selectively interfering with the performance subtests.

\section{Discussion}

The results suggest a resolution of the conflicting findings in published reports regarding discrepancies between verbal and performance IQs in Duchenne muscular dystrophy. A greater verbal impairment in relation to performance IQ was clearly observed in the younger dystrophics who were still physically active and in relatively good motor control. They scored on average 12 points higher on performance IQ than verbal IQ. In the older, more disabled dystrophics who were less facile with their hands, this difference was not observed.

In analysing the effect of disease severity on verbal and performance IQs by comparing the younger, less physically impaired dystrophics with the older, more disabled dystrophics, it becomes apparent that the impairment in verbal IQ is early and nonprogressive, whereas performance IQ shows no corresponding impairment early in the disease process but lower scores tend to emerge as the disease advances and are related to the severity of the disease process. The finding of an early, nonprogressive impairment of verbal IQ supports the contention of Rosman (1970) and Prosser et al. (1969) that there is a cerebral defect that is a genetically determined developmental abnormality appearing early in DMD, but contradicts Prosser et al.'s conclusion that the intellectual impairment is 
uniform, with both verbal and performance IQs equally impaired.

The main conclusion from this study is that the organic brain damage appears to be genetically determined, is present early in intellectual development, and tends to be verbal in nature.

The main implication of these findings is that when the dystrophic boy becomes wheelchair dependent he is probably penalized on the WISC Performance subtests because he is less agile with his hands. In estimating the intellectual functioning of the more severely physically handicapped dystrophics, it is well to keep in mind that their test results probably underestimate their abilities to some extent on the performance subtests. It is not suggested that the use of the performance subtests be discontinued in estimating intellectual functioning for either the mildly or more severely disabled DMD patient. Relying on the verbal IQ alone to estimate a dystrophic boy's intellectual functioning also tends to underestimate his actual intelligence, because it is in the area of cognitive functioning measured by the verbal subtests that the early cognitive impairment is noted. The recognition that the intellectual impairment is nonprogressive in nature leads to some important therapeutic considerations in that teachers should not assume that the intellectual capabilities will deteriorate as the child gets weaker and eventually becomes confined to a wheelchair.

We are greatly indebted to Maria Helgeson, for the collection and analysis of the data.

\section{REFERENCES}

Ackerman, P. T., Peters, J. E., and Dykman, R. A. (1971). Children with specific learning disabilities: WISC profiles. Fournal of Learning Disabilities, 4, 150.

Allen, J. E., and Rodgin, D. W. (1960). Mental retardation in association with progressive muscular dystrophy. American Fournal of Diseases of Children, 100, 208.

Barclay, A., and Carolan, P. (1966). A comparative study of the Wechsler Intelligence Scale for Children and the Stanford-Binet Intelligence Scale, Form L-M. Fournal of Consulting Psychology, 30, 563.

Clements, S. D., and Peters, J. E. (1962). Minimal brain dysfunction in the schoolage child. Archives of General Psychiatry, 6, 185.

Dubowitz, V., and Crome, L. (1969). The central nervous system in Duchenne muscular dystrophy. Brain, 92, 805.

Hannon, J. E., and Kicklighter, R. (1970). WAIS versus WISC in adolescents. Fournal of Consulting and Clinical Psychology, 35, 179.

Kozicka, A., Prot, J., and Wasilewski, R. (1971). Mental retardation in patients with Duchenne progressive muscular dystrophy. fournal of the Neurological Sciences, 14, 209.

Prosser, E. J., Murphy, E. G., and Thompson, M. W. (1969). Intelligence and the gene for Duchenne muscular dystrophy. Archives of Disease in Childhood, 44, 221.

Rosman, N. P. (1970). The cerebral defect and myopathy in Duchenne muscular dystrophy. Neurology, 20, 329.

Rourke, B. P., Young, G. C., and Flewelling, R. W. (1971). The relationships between WISC verbal-performance discrepancies and selected verbal, auditory-perceptual, visual-perceptual and problem-solving abilities in children with learning disabilities. fournal of Clinical Psychology, 27, 475.

Seashore, H., Wesman, A., and Doppelt, J. (1950). The standardization of the Wechsler Intelligence Scale for Children. fournal of Consulting Psychology, 14, 99.

Sherwin, A. C., and McCully, R. S. (1961). Reaction observed in boys of various ages $(10-14)$ to a crippling, progressive, and fatal illness (muscular dystrophy). Fournal of Chronic Diseases, 13, 59.

Terman, L. M., and Merrill, M. A. (1937). Measuring Intelligence. Houghton Mifflin, Boston; Harrap, London.

Wechsler, D. (1949). Manual for the Wechsler Intelligence Scale for Children. Psychological Corporation, New York.

Wechsler, D. (1955). Manual for the Wechsler Adult Intelligence Scale. Psychological Corporation, New York.

Zellweger, H., and Hanson, J. W. (1967). Psychometric studies in muscular dystrophy type IIIa (Duchenne). Developmental Medicine and Child Neurology, 8, 576.

Zellweger, H., and Niedermeyer, E. (1965). Central nervous system manifestations in childhood muscular dystrophy. I. Psychometric and electroencephalographic findings. Annales Paediatrici, 205, 25.

Correspondence to Dr. Gayle G. Marsh, Reed Neurological Research Center, 710 Westwood Plaza, Los Angeles, California 90024, U.S.A. 